\title{
Seasonal and spatial factors related to longitudinal patterns of child growth in Bwamanda, DR Congo
}

\author{
Catherine Schwinger ${ }^{1 *}$, Torleif Markussen Lunde ${ }^{1,2}$, Peter Andersen ${ }^{3}$, Hallgeir Kismul ${ }^{1}$ and Jan Van den Broeck
}

\begin{abstract}
Background: Studying the influence of geographical factors on child growth is important, especially given the increasing interest in climate change and health in resource-poor settings and the recognized importance of growth faltering as a general marker of population health. We describe patterns in children's weight and length velocity and relate them to seasonal and spatial factors in rural DR Congo. The study setting is a food-insecure area with a majority dependent on rain-fed subsistence farming and expected to be one of the regions most affected by climate change.

Methods: We studied the effect of selected geographical factors, i.e. season, village size and distances to hospital, health center, forest, fishing grounds and market on growth of children under two years old. We calculated individual growth velocity Z-scores according to the WHO-2009 growth velocity standards for up to five successive 3-month growth periods. Associations with geographical factors were examined in multivariate mixed effects regression models.

Results: For the study population of 2223 children is characterized by low nutritional status. Age and season were the only independent predictors of growth velocity in the multivariate regression analysis. Mean velocity Z-scores were already low in children aged 0-6 months for weight [-1.34 (95\% Cl: -1.45, -1.22)] and for length [-0.99 (95\% Cl: -1.13, -0.84)]. They increased with age, while Z-scores of attained growth gradually decreased. Mean growth velocities were lowest before the main harvest season with a mean improvement of 1.2 and 2.3 Z-scores for weight and length velocity thereafter. A seasonal pattern was not seen in attained growth. No relation to spatial factors was found.
\end{abstract}

Conclusions: In this rural subsistence economy area, geographical factors relating to distances to food sources and health services are less important determinants than harvest season, which is the major underlying determinant of child growth in these settings.

Keywords: Ecological factors; Growth velocity; Anthropometry; Climate; Nutritional status

\section{Background and objectives}

Experts are highly confident that existing high burdens of negative health outcomes associated with climate will be amplified by the expected climate change over the next decades (IPCC 2014; WHO and WMO 2012). Undernutrition, which is still a problem in many developing countries and, not only a major contributor to poor health (Black et al. 2008), but also associated with long-term consequences, such as cognitive impairment, immune defects

\footnotetext{
* Correspondence: c.schwinger@cih.uib.no

${ }^{1}$ Centre for International Health, University of Bergen, Årstadveien 21, 5009 Bergen, Norway

Full list of author information is available at the end of the article
}

etc. (Fishman et al. 2004; Schaible and Kaufmann 2007), is predicted to worsen globally, but especially in regions which are already food-insecure.

Undernutrition can be directly affected by climate, e.g. by drought, but also indirectly by a linkage to seasonal changes in weather and vegetation (Maleta et al. 2003). This is particularly pronounced in rural regions where subsistence farming is practiced and where energy intake as well as work intensity heavily depend on the seasonal cycle of agricultural production. Additionally, a higher morbidity load often coincides with the "hungry season", the season before harvest, when food stocks are running out. A complex of impaired immune system function, peaks

\section{实}


of disease vectors in the environment as well as agricultural work competing with child care, adds to the seasonality of malnutrition (Gill 1991). Vaitla et al. (2009) states that most of the world's undernutrition occurs, not as expected during periods of conflicts and extreme weather conditions, but periodically during this "hungry season". With the background that the first years of life are the most important but also the most vulnerable in terms of growth, disturbances of these seasonal factors have the potential to lead to permanent negative consequences for child survival and development.

The Democratic Republic of Congo (DRC) is one of the regions where the Intergovernmental Panel on Climate Change (IPCC) predicts a rise in temperature and a shortening of the rainy season (IPCC 2014). It also belongs to one of the regions in which the emergence of climate signals relative to the natural climate variability will occur first (around 2020-2030) (Hawkins and Sutton 2012; Mahlstein et al. 2011) and where the ecosystem is particularly vulnerable to climate change (Mahlstein et al. 2011). With a majority relying on rain-fed subsistence agriculture this is an alarming issue (UNEP 2011; Kandala et al. 2011) and is reason to shed renewed light on the relationship between season and child malnutrition.

Spatial parameters have been found to explain a reasonable amount of the variation in childhood mortality on a large scale in West-Africa (Balk et al. 2004) as well as rates of malnutrition in the DRC (Kandala et al. 2011). Despite the improved possibilities available to assess spatial parameters, there is still a scarcity of research including them (De Sherbinin 2011). In the DRC, where the proportion of malnourished children under 5 years increased to an alarming level with $46 \%$ being stunted and $10 \%$ being wasted in 2007 (Ministère du Plan et Macro International 2008), and where continued conflict, land degradation and collapsing infrastructure worsens the capacity to produce and trade food, understanding regional differences in child malnutrition are important to effectively establish interventions and develop nutrition policies (Kandala et al. 2011). However, there is a difference in scale between the regional inequalities studied before (Kandala et al. 2011) and the spatial determinants we attempt to analyze in the present study.

In children, who are regarded as one of the populations most affected by climate change (IPCC 2014), undernutrition is reflected in restrained growth (UNICEF 1998). Growth can principally be measured with two main approaches: attained growth at a specific age or longitudinal growth over a period of time. Longitudinal growth measured over a short period is considered to have the advantage over attained growth, in that it represents what is currently happening and not, as in attained growth, what has happened in the entire past up to the point in time of measurement. This offers the opportunity to detect faster any unusual growth in children, but also to study associations with potential risk factors while the child is in the actual process of growth faltering and not when the child has already faltered (Argyle 2003). One method to assess longitudinal growth is growth velocity. The WHO released growth velocity standards in 2009 (WHO 2009), which scores anthropometric measurements in reference to normal growth velocity in the specific age period. Despite the recognized advantages, these standards are rarely used in research yet.

Although the impact of geographical factors, particularly season, on the nutritional status and growth of children is not a new research questions, some authors advise caution as over-generalizations, due to a wide variation in microclimates and ecologies, can affect causal pathways and the degree of impact of seasonality (Ferro-Luzzi et al. 2001; Prentice and Cole 1994). Previous studies on seasonality of nutritional status and growth have been conducted in Asia (Brown et al. 1982; Carlquist et al. 1999; Hillbruner and Egan 2008; Jalil et al. 1989; Karlberg et al. 1993; Miller et al. 2013; Panter-Brick 1997; Xu et al. 2001), Africa (Maleta et al. 2003; Ferro-Luzzi et al. 2001; Chotard et al. 2010; Hauspie and Pagezy 1989; Kigutha et al. 1995; Loutan and Lamotte 1984; Rosetta 1988; Tomkins et al. 1986; McGregor et al. 1968; Wright et al. 2001; Lindtjorn et al. 1993) and South-America (Marin et al. 1996), but they report inconsistent findings. Additionally, only one of the above-mentioned studies used the WHO standards to score growth (Miller et al. 2013). That study finds irregular associations with season depending on the anthropometrical measure used. They argue that even significant differences between seasons were small in absolute terms and should be interpreted cautiously due to possible bias, for example by the state of hydration, clothing etc. influencing weightbased indices. Comparisons of the WHO standards and previously used growth references show that important differences exist in identifying malnourished children, but also in age patterns of growth (de Onis et al. 2011).

This work aims to contribute to the understanding of growth velocity in children in relation to geographical factors in rural Africa. The objectives of this paper are to describe age- and sex-dependent patterns in weight and length velocity of children younger than two years living in the DRC using the WHO Child Growth Standards (WHO 2009) and to relate these patterns to selected climatic and spatial determinants, with a main focus on season and distances to sources of food and health care, and with the specific concern to examine the relative importance of those.

\section{Methods}

\section{The original Bwamanda study}

To address our research question, we did a secondary analysis of data collected in the Democratic Republic of Congo (DRC; formerly Zaire). Research setting and methods of 
participant enrollment and data collection are described in detail elsewhere (Van den Broeck 1994). In brief, a dynamic population study was conducted in the health zone of Bwamanda from August 1989 to March 1991. This health zone is one of 16 administrational zones within the Sud-Ubangi district, which is one of four districts in the Equateur province in the northwest of the country. Bwamanda has a tropical climate with two main seasons a rainy season from March to November and a dry season from December to February. Up until today it is a rural area and over $90 \%$ of households practice traditional subsistence farming with maize and cassava as the main staple foods. Subsistence farming is highly dependent on geographical factors, such as soil quality, infrastructure and water availability (UNEP 2011; Morton 2007). Diets are rather monotonous, typically consisting of gruels from cassava and maize. The carbohydrate rich staples are to various degrees supplemented with smaller amounts of more nutrient dense green leaves, vegetables, legumes and animal source foods, and we anticipate that the main difference between adequately nourished and malnourished households is found in access to these nutrient dense foods. These factors, amongst others, contribute to the common problem of malnutrition in this community (Van den Broeck 1994).

Sixteen out of 52 villages in the Bwamanda health zone were selected in a random cluster sample procedure. A preliminary census based on home visits was carried out in August and September 1989 and 4238 children aged 0-5 years and their mothers were enrolled in the study. Simultaneous training of 15 interviewers, holding a secondary school certificate, was done at Bwamanda hospital by a medical doctor. Between October 1989 and March 1991 six surveys were carried out measuring each child at three-month intervals (rounds A-F), all at special under-5 clinics, or, if children were not present at the clinics, at house-to-house visits. In total 5657 children under the age of 5 were enrolled during the study period. Variables recorded in each of the six quarterly surveys included the results of a clinical examination, anthropometric measures (including weight, height or length and mid-upper-arm-circumference), data on interval-morbidity, mortality, harvest and feeding practices, socioeconomic conditions, and environmental information, such as distances from the village to health care and food sources. In addition emigration and temporary absence during the study period was recorded. Data collection was continuously overseen by two medical doctors. Age was obtained using the birthdates documented on the 'road to health charts' or the identity papers of the parents. If this information was lacking (in ca. $10 \%$ of the children), careful interviews of the mothers were used in combination with a local calendar to estimate the child's date of birth.

\section{Geographical factors}

According to the conceptual framework of child malnutrition developed by UNICEF (1998), risk factors can be assigned to basic, underlying and immediate level, all of which are interrelated with each other. In Bwamanda, the study area, characteristics reflecting the basic cause level (cultural, political, and economical structures) are considered to be relatively homogeneous. We selected geographical location and season as a proxy for underlying factors such as access to and availability of different sources of food and health care, and a healthy environment due to varying amount of germs and pathogens in different seasons. Spatial factors considered were village size and distance from the village to health center, hospital, market, fishing grounds, and the forest, as a proxy for access to bush foods. Inter-individual differences due to varying dietary patterns and morbidity, the immediate causes, are not accounted for in this analysis as they are mediators of the underlying causes in our epidemiological understanding. Including them would dilute the relationship between underlying factors and malnutrition.

Season in this setting is best described in terms of variation in precipitation, since temperature and daily sunshine hours do not differ much throughout the year. Seasons were defined as rainy season (1st March-30th November) and dry season (1st December-28th February). This definition differs from former analyses on this dataset (Van den Broeck 1994; Garenne et al. 2009). The adjustment was performed after analyzing data on precipitation obtained from a local weather station, which were additionally supported by satellite estimates (see Additional file 1), and published precipitation data from a nearby weather station (Franquin et al. 1988). The classification into preand post-harvest was based on information from the original study on harvest of the main food items cassava, cassava leaves, maize, sweet potato, taro, peanuts and bananas in the last two months. Although harvest is possible twice a year for maize and several times for cassava and cassava leaves, we used timing of the first main harvest for the classification of sub-season. This classification was confirmed by informal talks to local farmers and the responsible person for agricultural development in the NGO CDI Bwamanda, which specializes in integrated sustainable livelihood development and has been working in the study area since 1969.

\section{Anthropometric measurements}

Anthropometric measurements were taken following a standardized procedure by two experienced observers. Weight was taken with spring scales (Continental Ltd., United Kingdom) to the nearest 100 grams. Height was measured with a microtoise reading to the nearest millimeter while length was measured with a locally built measuring board. Mid-upper-arm circumference (MUAC) was 
taken by the same medical doctor with a steel tape measure (Stanley) to the nearest millimeter.

\section{Anthropometric scoring}

Weight and length velocity were calculated for each successive 3-month follow-up period. Raw values were scored according to the WHO Child Growth Standards (WHO 2009) using a macro provided by O'Neill et al. (2012). The analysis was restricted to children of the age 0-24 months, because the WHO-2009 standards are only available for this age range. Weight and length velocity were categorized on the basis of whether and when Z-scores were higher or lower the -2 to +2 normal Z-score range. Growth was defined as "slow" when the Z-score was $\leq-2$, as "normal" when the Z-score was $>-2$ and $<2$ and as "rapid" when it was $\geq 2$.

In order to compare the velocity Z-scores to indices of attained growth, we also calculated Z-scores for attained weight-for-age (WAZ), length-for-age (LAZ), weight-forlength (WLZ) and mid-upper-arm-circumference-for-age (MUAZ) according to the corresponding WHO child growth standards (WHO 2006, 2007). Wasting is defined as $\mathrm{WAZ}<-2$ and stunting as $\mathrm{LAZ}<-2$.

\section{Statistical methods}

For this analysis the original dataset was imported into SPSS (Statistical Package for the Social Sciences) version 19.0.0 and kept in a secure place to ensure confidentiality. Data cleaning was performed before commencing the analysis. Attained growth Z-scores $<-6$ and $>6$ as well as 3 -month velocity $Z$-scores in weight and length of $<10$ and $>-10$ were defined as implausible and set as missing. Of a total of 46694 measurements 69 values for WAZ, LAZ, WLZ and MUAZ and eight values for weight and length velocity $Z$-scores were set as missing.

A bivariate analysis was carried out to establish the associations between growth velocity and the geographical determinants. In addition, multivariate mixed effect regression models, with an unstructured variance-covariance matrix, were developed. These models differed from conventional mixed effect models in growth analysis in that they do not use attained growth Z-scores but instead growth velocity Z-scores in successive periods. Modeling growth velocity Z-scores has the advantage that it accounts for different growth rates at different ages. That is important, because infants grow faster the younger they are, so that the same differences in attained Z-score for a certain period of time has a different meaning for different ages. For example a change of $+0.25 \mathrm{Z}$-scores from age $0-3$ months and from 3-6 months indicates a greater change in the older infant, since growth is normally slower compared to the younger infant. However, when modeling attained growth Z-scores this differences of +0.25 would be treated as equal acceleration of growth, when in reality it is not.
Variables for age, sex, birth-rank, mother's age and breastfeeding status (no breastfeeding, exclusive or complementary breastfeeding) were initially taken into the model as covariates, but omitted if they were not statistically significant.

\section{Ethics}

Ethical approval for the original study was obtained by the University of Leuven's Tropical Childcare Health Working Group. This current analysis was approved by the Ethical Committee at the University of Kinshasa (approval number: $\mathrm{ESP} / \mathrm{CE} / 008 / 14)$.

\section{Results}

Of the 5657 children enrolled in the study, 2223 were under the age of two years at two or more measurement points and eligible for growth velocity calculations. The sample was homogeneous in ethnicity (97.7\% were Ngbaka) and balanced in sex (49.3\% female). Birth-rank ranged from 1 till 15. The age of the mother at the time of child birth varied between 13 and 56 years with a median of 27 years (interquartile range 22-32). Other demographic and anthropometric characteristics are summarized in Table 1 . The 16 selected villages had on average about 1600 inhabitants each (between 900 and 2000). The distance from the village to the market was between $200 \mathrm{~m}$ and $30 \mathrm{~km}$, to the hospital between $500 \mathrm{~m}$ and $65 \mathrm{~km}$, to fishing grounds between $150 \mathrm{~m}$ and $6 \mathrm{~km}$ and to the forest between $150 \mathrm{~m}$ and $15 \mathrm{~km}$.

\section{Growth velocity patterns}

Mean (SD) velocity Z-scores according to the WHO2009 standards were -0.70 (1.55) for weight and -0.87 (1.90) for length for all children included and all five study periods taken into account.

Indices of attained growth clearly showed tracking in individuals, i.e. measurements were strongly positively correlated with consecutive measurements throughout the study period. In contrast, growth velocities varied in consecutive periods, so that velocities in one 3-month period were negatively correlated with the velocities in the adjacent 3-month period, both before and after. These correlations were significant for all periods for length velocity. Weight velocities showed the same pattern, but the negative correlations were weaker and partly insignificant. Growth velocities showed an association with corresponding indices of attained growth, in that they correlated negatively with the attained Z-score in up to four periods before and positively in up to five periods after the velocity measurement.

Growth velocities were categorized as "slow", "normal" and "rapid" growth according to the criteria described in the Methods section. Over the total study period, $16.5 \%$ of the 3-month growth periods for weight of all children 
Table 1 Demographical and anthropometrical characteristics of the study sample $(\mathrm{N}=2223)$ in the different survey rounds

\begin{tabular}{|c|c|c|c|c|c|c|c|}
\hline \multirow{2}{*}{\multicolumn{2}{|c|}{ Number of children analyzed }} & Round A & Round B & Round C & Round D & Round E & Round F \\
\hline & & 1293 & 1505 & 1734 & 1957 & 2223 & 2223 \\
\hline \multicolumn{2}{|c|}{ Average age in months (SD) } & $11.2(6.4)$ & $12.3(7.0)$ & $13.3(7.7)$ & $14.6(8.4)$ & $16.8(9.5)$ & $20.0(9.6)$ \\
\hline \multicolumn{2}{|l|}{ Mean LAZ (SD) } & $-1.86(1.39)$ & $-1.98(1.35)$ & $-1.87(1.33)$ & $-2.03(1.29)$ & $-2.26(1.25)$ & $-2.34(1.17)$ \\
\hline \multicolumn{2}{|l|}{ Mean WAZ (SD) } & $-1.24(1.23)$ & $-1.24(1.18)$ & $-1.30(1.18)$ & $-1.44(1.20)$ & $-1.54(1.16)$ & $-1.52(1.06)$ \\
\hline \multicolumn{2}{|l|}{ Mean WLZ (SD) } & $-0.24(1.20)$ & $-0.12(1.15)$ & $-0.30(1.17)$ & $-0.37(1.14)$ & $-0.31(1.11)$ & $-0.26(1.01)$ \\
\hline \multicolumn{2}{|l|}{ Mean MUAZ (SD) } & $-1.72(1.10)$ & $-1.72(1.06)$ & $-1,84(1.08)$ & $-2.01(1.11)$ & $-2.23(1.12)$ & $-2.12(1.00)$ \\
\hline \multirow[t]{2}{*}{ Stunted (\%) } & Moderate & 25.7 & 28.2 & 28.5 & 29.0 & 32.3 & 33.1 \\
\hline & Severely & 19.6 & 22.1 & 18.4 & 21.8 & 27.1 & 27.8 \\
\hline \multirow[t]{2}{*}{ Underweight (\%) } & Moderate & 17.6 & 16.3 & 18.6 & 20.9 & 23.8 & 22.6 \\
\hline & Severely & 7.1 & 7.2 & 7.7 & 10.1 & 10.5 & 8.3 \\
\hline \multirow[t]{2}{*}{ Wasted (\%) } & Moderate & 5.4 & 4.6 & 5.3 & 5.2 & 5.0 & 4.2 \\
\hline & Severely & 1.5 & 0.9 & 0.9 & 1.7 & 1.4 & 0.5 \\
\hline \multirow[t]{2}{*}{ Low MUAZ (\%) } & Moderate & 28.5 & 27.6 & 27.8 & 31.0 & 34.4 & 36.9 \\
\hline & Severely & 11.8 & 10.9 & 14.8 & 18.2 & 23.6 & 17.8 \\
\hline
\end{tabular}

Stunting is defined as low length-for-age Z-score (LAZ), underweight as low weight-for-age Z-score (WAZ), wasting as low weight-for-length Z-score (WLZ) and low MUAC as low mid-upper-arm-circumference-for-age Z-score (MUAZ) according to the WHO Child Growth Standards. Cut-offs for moderate malnutrition were set to $\leq-2$ and $>-3 Z$ Z-score, and for severe malnutrition to $\leq-3 Z$-score.

were within the slow growth category, $81.4 \%$ within the normal range and $2.1 \%$ within the rapid growth category. For length velocity Z-scores $24.1 \%, 70.9 \%$ and $5 \%$ of the periods were within the slow, normal and rapid category, respectively.

Further we were interested to see if children were able to counterbalance slow growth in one period by fast growth in the next period or the other way around, i.e. rapid growth in one period followed by slow growth in the next period. Therefore, we looked at two subsequent assessment periods of growth velocity. For weight it was observed that slow growth was infrequently followed by rapid growth (in 5\% of the children). Mostly the second value was within the range of normal growth $(82 \%)$ or stayed slow (13\%). If a child had a normal growth velocity, it was more likely that in the following period the velocity would also be normal (86\%), with 13\% showing slow growth and $1 \%$ rapid growth. And after a period of rapid growth, the children were showing either slow or normal growth in the next period (39\% and 59\%). In summary, weight did not show distinct catch-up growth, defined as growth velocity exceeding statistical limits of normal growth, after a period of restrained growth. In contrast, length velocities showed more "balancing". After a period of slow linear growth it was more common that children had a rapid length growth in the following period (30\%) compared to weight, and periods with rapid length growth were mostly followed by one with slow growth (55\%).

\section{Growth velocity according to age and sex}

After stratifying according to ages 0-6, 7-12 and 13-24 months, mean velocities were compared (Table 2). Children in the oldest age category had the highest velocity Z-scores for weight and length compared to the two other age categories. The differences in mean velocities were not statistically significant between ages $0-6$ and 7-12 for

Table 2 Indices of growth in three age-categories and according to sex for all survey rounds combined

\begin{tabular}{|c|c|c|c|c|c|c|}
\hline \multirow[t]{2}{*}{$\begin{array}{l}\text { Age category } \\
\text { (in months) }\end{array}$} & \multicolumn{4}{|c|}{ Attained growth mean Z-score $(95 \% \mathrm{Cl})$} & \multicolumn{2}{|c|}{$\begin{array}{l}\text { Longitudinal growth mean } \\
\text { Z-score }(95 \% \mathrm{Cl})\end{array}$} \\
\hline & WAZ & LAZ & WLZ & MUAZ & Weight velocity & Length velocity \\
\hline $0-6$ & $-0.96(-1.03,-0.89)$ & $-1.41(-1.48,-1.33)$ & $0.16(0.09,0.23)$ & $-1.54(-1.60,-1.48)$ & $-1.34(-1.45,-1.22)$ & $-0.99(-1.13,-0.84)$ \\
\hline $7-12$ & $-1.49(-1.55,-1.44)$ & $-2.00(-2.05,-1.93)$ & $-0.46(-0.51,-0.40)$ & $-1.95(-2.00,-1.89)$ & $-0.77(-0.84,-0.69)$ & $-1.01(-1.12,-0.91)$ \\
\hline $13-24$ & $-1.50(-1.54,-1.47)$ & $-2.38(-2.42,-2.34)$ & $-0.44(-0.48,-0.41)$ & $-1.97(-2.00,-1.94)$ & $-0.38(-0.44,-0.32)$ & $-0.67(-0.74,-0.60)$ \\
\hline Female (all ages) & & & & & $-0.64(-0.70,-0.58)$ & $-0.85(-0.93,-0.77)$ \\
\hline Male (all ages) & & & & & $-0.69(-0.75,-0.62)$ & $-0.81(-0.89,-0.73)$ \\
\hline
\end{tabular}

Reported are mean Z-scores with 95\% confidence intervals. Z-scores for weight-for-age (WAZ), length-for-age (LAZ), weight-for-length (WLZ), mid-upper-arm-circumference-for-age (MUAZ), weight velocity and length velocity are scored according to WHO Child Growth Standards (WHO 2006, WHO 2007, WHO 2009). Age is given in months. 
length velocities. Attained Z-scores showed a downwards trends, i.e. the youngest age category had a significantly higher mean Z-score in all four indices (WAZ, LAZ, WLZ, MUAZ) than the older age categories. The two older age categories did not differ except in mean LAZ.

Weight and length velocity Z-scores did not differ significantly according to sex (Table 2). Figure 1 shows mean velocities according to sex and age category. Although error bars indicating the $95 \%$ CI overlap at all ages, the difference in sex for the age group 7-12 months is significantly different for weight velocity $(\mathrm{t}=2.622, \mathrm{p}=0.009)$.

\section{Associations between growth velocity and spatial parameters}

There were no significant associations between growth velocity $\mathrm{Z}$-scores for weight and length and the variables indicating the size of the village, and the distances to health center, market, hospital, fishing grounds, and the forest (Table 3). No differences were seen when stratified according to sex and age category. Also the occurrence of catch-up growth did not differ when comparing the quintile nearest to the hospital, market, fishing grounds and forest with the quintile farthest from those points.

\section{Associations between growth velocity and season}

Mean growth velocity Z-scores were lowest in the preharvest season, namely between March and July, and improved after the first main harvest in July (Figure 2) with a mean improvement of 1.2 and 2.3 Z-scores for weight and length velocity. This was also seen by a rise in the portion of growth velocity Z-scores categorized as slow growth and a decrease in the portion of rapid growth until the harvest season. Although weight and length velocities showed the same general pattern, mean length velocities deteriorated more markedly than mean values in weight velocity and the increase in mean length velocity at the beginning of the post-harvest season was slower than the increase of weight velocity. Length velocity peaked about two months after weight velocity.

A seasonal pattern could not be clearly seen in attained growth. No differences in the effect of season on longitudinal growth between the sexes were observable (Figure 2), nor between age categories. There was no seasonality in the occurrence of catch-up growth when defined as growth velocity $\mathrm{Z}$-score $>+2$.

\section{Multivariate analysis}

We built mixed models with an unstructured variancecovariance matrix allowing for random intercepts for each individual child. Velocity Z-scores in weight or length were entered as dependent variables. Independent variables were season, size of village, distance to hospital, health center, market, fishing grounds and forest, age, sex, breastfeeding status, birth-rank and mother's age at birth. This multivariate analysis confirmed our findings from bivariate analysis, i.e. that age and season were the only independent predictors. Breastfeeding was a significant predictor, but did not improve the fit of the model significantly.

\section{Discussion}

The data from the Bwamanda study, which are still of high relevance today, and the newly published WHO growth velocity standards offered a unique opportunity to study longitudinal growth over up to five successive 3-month periods of 2223 children between $0-2$ years in relation to seasonal and spatial factors, which are of increasing interest.
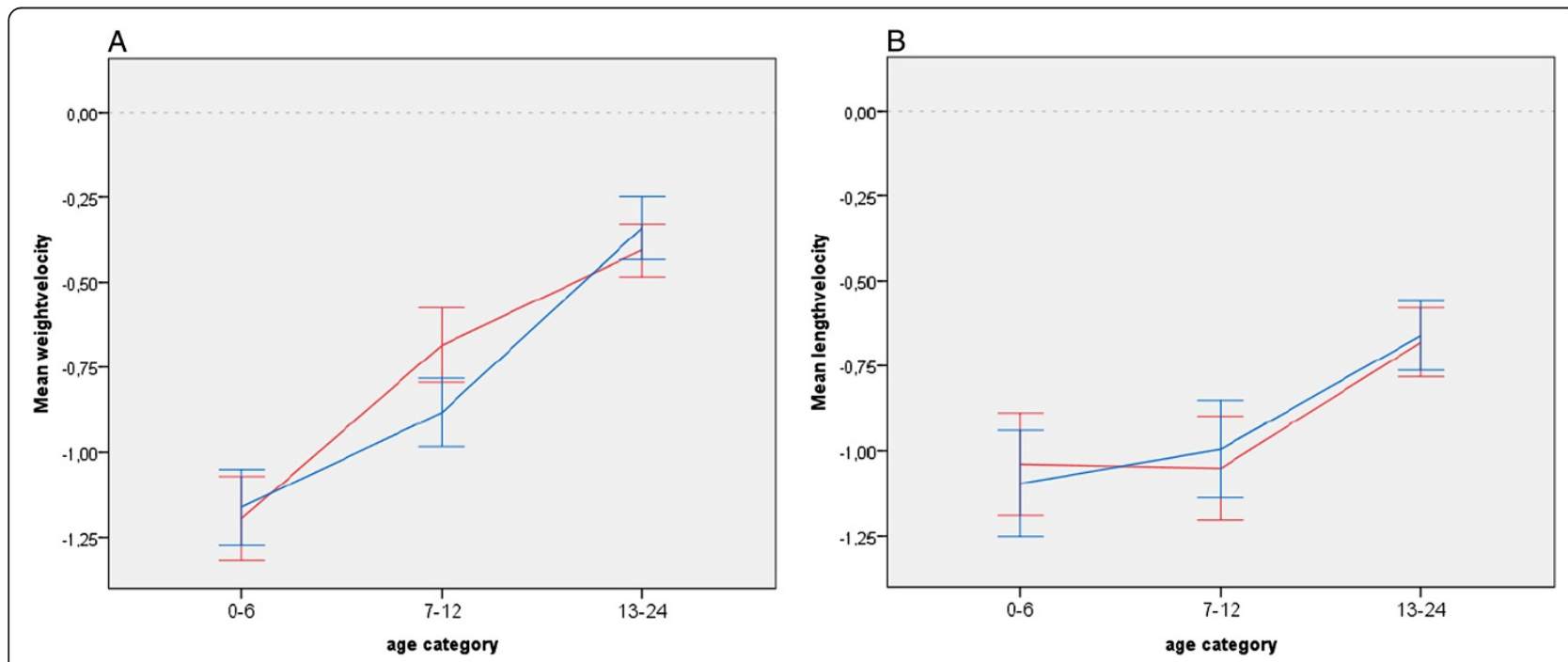

Figure 1 Mean weight velocity (A), mean length velocity (B) according to age-category and sex. Error bars indicate the $95 \%$ confidence interval. Girls are represented by a red line and boys by a blue line. Age is given in months. 
Table 3 Correlations between indices of longitudinal growth and spatial parameters

\begin{tabular}{lllll}
\hline & $\begin{array}{l}\text { Weight } \\
\text { velocity }\end{array}$ & $\mathbf{p}$ & $\begin{array}{l}\text { Length } \\
\text { velocity }\end{array}$ & $\mathbf{p}$ \\
\hline Village size & 0.006 & 0.683 & 0.024 & 0.083 \\
Distance to market & 0.000 & 0.991 & -0.015 & 0.293 \\
Distance to hospital & 0.016 & 0.240 & -0.010 & 0.494 \\
Distance to fishing ground & 0.004 & 0.790 & -0.015 & 0.298 \\
Distance to forest & 0.009 & 0.501 & -0.026 & 0.060 \\
\hline
\end{tabular}

In order to study longitudinal growth of children, we described patterns for age- and sex-dependent growth velocity Z-scores for weight and length. We find that growth velocity Z-scores for weight and length were strongly related to season while no index was related to the selected spatial parameters in our sample. The seasonal impact could not be demonstrated in attained growth. This and the fact that a restriction in growth showed much earlier when studying growth velocity Z-scores, argue for longitudinal growth as an important tool in the timely detection of growth faltering. It also points to a limitation of many previous studies of the relation between geographical factors and growth.

\section{Patterns of longitudinal growth}

Poor nutritional status was common in our sample, reflected by around $52 \%$ stunted and $6 \%$ wasted children in each survey round. This was also observable in the percentage of children with velocity Z-scores under what is usually defined as the normal range $(Z$-score $<-2)$. $16.5 \%$ and
24.1\% had a slow growth in weight and length respectively. Analyses of child growth in low- and middle-income countries show that growth faltering starts early in life and worsens up to the age of two years (Victora et al. 2010). In our sample we also see continuous deteriorating indices of attained growth despite increasing velocities with age. This finding underlines the importance of early interventions.

Length velocities of successive periods were more strongly negatively correlated than weight velocities and when looking at two consecutive periods, we found that periods with slow length velocities were more often followed by rapid growth (indicating catch-up growth) and vice versa (catch-down growth) than in ponderal growth. This suggests that length velocity is more variable than weight velocity. Nevertheless, the corresponding index for attained growth (LAZ) still deteriorated over time. Catch-up growth can be defined as growth that statistically exceeds normal growth (i.e. $>+2$ Z-scores). The periods with rapid growth following those with slow growth were probably not strong enough, and there were still many more children who after a period with slow growth had growth velocities within the normal growth range and therefore no catch-up growth, as defined above. It has to be mentioned that this description does not take into account any confounding factors and cannot therefore suggest any causes of the longitudinal behavior. Physiological growth is characterized by variation within the normal range in growth velocities in subsequent periods (WHO 2009), so it is difficult to interpret only a single growth velocity of an individual. It is thus necessary to study further patterns of growth velocity for individual children in consecutive growth periods to gain insight and guidance in the evaluation of longitudinal growth for clinical use and research.
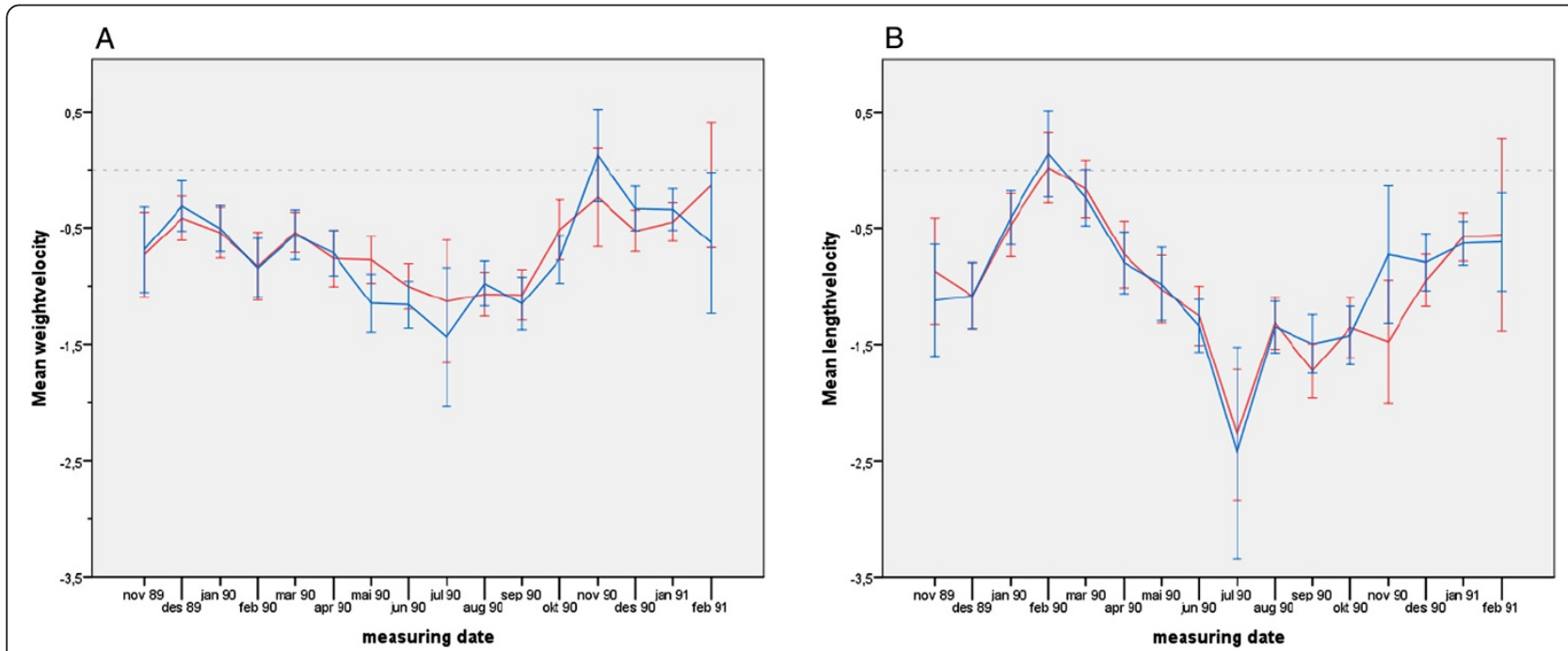

Figure 2 Mean weight velocity (A), mean length velocity (B) according to measuring date and sex. Error bars indicate the $95 \%$ confidence interval. Girls are represented by a red line and boys by a blue line. 


\section{Longitudinal growth according to sex, breastfeeding status and birth rank}

When comparing mean growth velocities no differences were seen between boys and girls. After stratifying for age, boys aged 7-12 month had a significantly lower mean weight velocity Z-score than girls. This difference was not observed in the older age group. This could either illustrate a better ability for the boys to catch-up or a survivor bias. But neither mortality nor catch-up growth showed a difference between the sexes in this sample. We do not have any information about intra-household and gender disparities in food and dietary composition for our sample. Olusanya and Renner (2011) found in their study sample composed of 658 Nigerian children 0-8 weeks old that male gender is an independent predictor of higher weight velocity. They argue that boys usually have larger growth increments than the same aged girls (WHO 2009; Guo et al. 1991; van't Hof et al. 2000), but since weight and length gains were not scored according to the WHO-2009 standards, this argument is invalid for our sample.

Breastfeeding status was significantly associated with growth velocities, but did not improve the multivariate model. This could be explained by almost universal exclusive breastfeeding up to the age of four months in our study sample and a weaning period thereafter as described previously (Van den Broeck et al. 1996). Therefore breastfeeding status might not add to the fit of the model as there is too little variation and the mechanism is already captured by the age variable.

Birth-rank was not associated with growth velocity Zscores and did not mitigate the effect of season in our study. In Bwamanda large household usually divide into three groups during the major meals: (i) children below the age of three, who eat with their mothers and other females in the household, (ii) those children above three years, who eat with other children, and (iii) adult males. A problem could arise in the group of children eating together (group ii), where there is competition and some discrimination against younger children, but for the age span we analyzed (0-24 months) this is not considered to be likely. Even if the younger family members did lose out during family meals, this is likely to be constant throughout the year independent of the total amount of food available and would therefore not affect the relation between season and growth.

\section{Associations with season}

The analysis of mean weight velocities shows that Zscores decreased in pre-harvest and increased in postharvest season. The same is true for length velocities, only peak velocity lagged by about two months. This lag is also described by Maleta et al. (2003) and Xu et al. (2001), who find that height gains peaked three months after weight gain. Some authors explained the lag as an effect of wasting on subsequent stunting, i.e. that a certain cut-off in weight-for-height has to be reached before compensatory linear growth appears (Costello 1989; Walker and Golden 1988). Although weight-for-height is also associated with weight gain in the study of Maleta et al. (2003), it only explains very little of the variation in height gain. Therefore other factors might play a more central role in linear growth.

We could not demonstrate a different impact of season in the age three groups $0-6,7-12$ months and 13-24 months. This is in accordance with the study by Hauspie and Pagezy (1989) in Zaire, who saw the same seasonal pattern in all age groups of 0-4 years. Age-dependency is reported by other studies (Maleta et al. 2003; Jalil et al. 1989; Karlberg et al. 1993; Miller et al. 2013; Rosetta 1988; McGregor et al. 1968), but with inconsistent results. The lack of differences related to age in our study might be due to the typical early weaning of children at around four month of age on average, resulting in less protection from environmental vectors and less mediation through maternal health.

Seasonality was not seen in indices of attained growth (WAZ, LAZ, WLZ). Our analysis suggests that it is important to study longitudinal growth and to associate factors when the growth of a child is actually faltering. This is supported by the work of Kismul et al. (2014) who find a seasonality in the incidence of wasting and stunting in children under five years in the same area. The lower responsiveness to season of length-for-age in comparison to length gains has been identified by others (Brown et al. 1982; Miller et al. 2013; Tomkins et al. 1986), but not for weight-based indices.

\section{Associations with spatial parameters}

Spatial parameters selected for this analysis were village size and distance from the village to health center, to the hospital, to a market, to fishing grounds and to the forest. None of them contributed essentially to differences in growth velocities in our sample, although they differed substantially for individual participants and could be expected to be of importance, especially in areas like the study setting, where only restricted motorized transport is available for local people.

Other studies, have found that population density has a close relationship with child malnutrition, explained by lower market penetration, and more limited access to health facilities and nutrition-related information (De Sherbinin 2011; Nikoi and Anthamatten 2013). In our setting, the scale was very different with a relatively homogenous village size, ranging from about 900 inhabitants to about 2000. Nevertheless, accessibility was different with some villages near the main road and local markets and others far off and difficult to reach, due to almost impassible roads, especially during the 
rains. Nevertheless, the whole region mainly comprises subsistence farmers producing only a minimal portion of cash crops. Therefore distance to market as well as size of village as an indication of connectivity or food availability, seem less important than size of the extended family, forming the working capacity to cultivate the fields. Quantity of cultivatable land is only of relevance if adequate working capacity exist, also having an impact on the quality of the harvested foods.

Low cash income may be one of the reasons why distance to the hospital, which varied greatly, did not have an impact on growth velocities, for even if the hospital was accessible, it is of no benefit if one cannot afford it. Local health centers, which where more accessible for all children and less expensive, did not show any impact on child growth velocities either. From our own experience in this region, health centers have variable resources in terms of medical equipment, medication, and training of their staff. Also the use of traditional healers has not been adjusted for in this analysis.

Similar arguments could be used for the association of distance to fishing grounds, which we were not able to show. Distance to fishing grounds was included in the analysis as a proxy for the availability of fish and therefore a source of animal protein-rich food. Although distance might determine the possibility for fishing, informal talks to people in the area indicated that even if people lived near fishing grounds, the lack of money to purchase fishing equipment stopped them from fishing.

Using distance to forests as a proxy for bush food did not generate correlations. Since fallow fields and other areas may be important sources of nutrient-dense supplementary foods, other measures of access to these resources should be developed.

\section{Limitations}

In addition to the limitations already discussed above, some uncertainties in measuring age, date and climatic data have to be reported. The exact age was documented for $90 \%$ of the 5657 children; in the remaining 10\% it was obtained through careful interviews with the help of local calendars. Even if some inaccuracy persists in this small portion of the children, it is not expected to substantially influence the results.

Data on the date of measuring was derived from adding the age in days to the birthdate, assuming that every month has 30.43 days. This will add some minor inaccuracies, but measuring date was only used to categorize the timing of measurements into seasons. Season is not a construct with clear borders, going from dry season to rainy in one day, and therefore only a few misclassifications with no substantial effects are expected.

Precipitation data was derived from triangulation of data from a local weather station, satellite data and published data from a nearby meteorological station. Nevertheless, no data for the specific study years were available, only long-term data from 1941-2005 and detailed data for the years 2001-2005. Weather conditions deviating from the normal in the study years could not therefore be accounted for.

The measure of harvest to define sub-seasons also has to be evaluated critically. Data on harvest was obtained by asking the interviewee if they had harvested a specific food item in the past two months. This rather long recall period is susceptible to recall bias. Further the possibility of information bias exists, since only two months of the average 3-month period between survey rounds are covered. However, the estimate still gives a good idea of the timing of harvest, since different households were interviewed every day and the purpose was not to assess the exact amount of harvest, but the timing, which we believe can be adequately recalled for the last two months. In addition, timing was confirmed by informal talks to local specialists. Analysis of the amount harvested compared to the amount eaten or sold assessed with a 24-hour recall, confirmed that it is an adequate indicator of food availability, because neither storing nor selling was common (data not shown).

A weakness in our study is the fact, that we did not include birth weight in our analysis. As mentioned in previous work (Van den Broeck et al. 1996), the majority of births took place at home with the help of a traditional birth attendant and it was therefore impossible to record birth weight for our study sample. Birth weight deviating from the normal is known to affect early child growth rates, representing catch-up or catch-down growth (WHO 2009). Births were almost evenly distributed throughout the year in our study, so varying growth rates in early childhood are not expected to change the relationship between season and growth velocities to a substantial extent.

\section{Conclusions}

In our analysis, we demonstrate that studying growth velocities instead of attained Z-scores can provide an important perspective concerning the early detection of growth faltering, because even if nutritional status measured by attained growth was deteriorating with age in our study sample, a restriction in growth could already be seen in much younger ages. Looking at growth velocities also revealed a clear seasonal impact on growth, which was not observable in attained growth.

In our study area, a rural subsistence economy, geographical factors relating to distances to food sources and health services seem less important determinants of child growth than harvest season, which is the major underlying determinant of child growth in these settings and is in turn is a geographical factor expected to be influenced greatly by climate change. Having such a negative impact on child growth in a supposedly pre-climate change situation, the 
perspective of climate changes taking place in this area and thus a change in the seasonal conditions for agricultural success is alarming. Additionally, the term transitory food-insecurity is often used for non-permanent, shortterm lack of food (Pinstrup-Andersen 2009) as in our described setting. But only in a few areas was it shown that weight gain exceeded the reference mean in seasons with less nutritional stress or morbidity burden and children thus maintained a satisfactory nutritional status in the long-term (Loutan and Lamotte 1984; Tomkins et al. 1986). In most other areas a further deterioration of nutritional status and long-term consequences are expected from those seasonal variations and therefore the expression transitory food-insecurity might be misleading.

As Wand et al. (2012) state, prevention and treatment of restricted growth in early childhood is central to enhancing social and economic development in low income countries, and approaches are likely to be successful if they allow for local factors. Our study indicates that agricultural season is an important factor for child growth, and thus targeting of local strategies to cope with seasonal conditions are crucial, especially in the light of predicted future risk related to climate change.

\section{Additional file}

Additional file 1: Monthly mean precipitation from observations and satellite estimates in the area of Bwamanda, DR Congo.

\begin{abstract}
Abbreviations
DRC: Democratic Republic of the Congo; LAZ: Length-for-age- Z-score; IPCC: Intergovernmental Panel for Climate Change; km: Kilometer; LVZ: Length-velocity Z-score; m: Meter; MUAC: Mid-upper-arm-circumference; MUAZ: Mid-upper-arm-circumference-for-age Z-score; SD: Standard deviation; WAZ: Weight-for-age-Z-score; WHO: World Health Organization;

WLZ: Weight-for-length Z-score; WVZ: Weight velocity Z-score.
\end{abstract}

\section{Competing interests}

The authors declare that they have no competing interests.

\section{Authors' contributions}

CS conducted the analysis and wrote the first draft of the manuscript. TML provided the supplementary material. All authors edited the manuscript and contributed in the interpretation of the results. All authors read and approved the final manuscript.

\section{Acknowledgements \\ The original research was supported by CDI-Bwamanda and funding was provided by Flemish Inter-University Council (Vlaamse Interuniversitaire Raad) the Belgian Administration for Development Co-operation, and the Nutricia Research Foundation. Roger Eeckels and JVdB initiated the original study and were responsible for data acquisition. All authors of this study were employed and funded by the University of Bergen. The funding body had no influence on the study design, data collection, analysis, interpretation of data or in the writing of the manuscript and the decision to submit the manuscript for publication.}

\section{Author details}

${ }^{1}$ Centre for International Health, University of Bergen, Årstadveien 21, 5009 Bergen, Norway. ${ }^{2}$ now at StormGeo AS, Bergen, Norway. ${ }^{3}$ Department of Geography, University of Bergen, Bergen, Norway.
Received: 24 April 2014 Accepted: 8 October 2014

Published online: 18 November 2014

\section{References}

Argyle J (2003) Approaches to detecting growth faltering in infancy and childhood. Ann Hum Biol 30:499-519

Balk D, Pullum T, Storeygard A, Greenwell F, Neuman M (2004) A spatial analysis of childhood mortality in West Africa. Popul Space Place 10:175-216

Black RE, Allen LH, Bhutta ZA, Caulfield LE, de Onis M, Ezzati M, Mathers C, Rivera $J$ (2008) Maternal and child undernutrition: global and regional exposures and health consequences. Lancet 371:243-260

Brown KH, Black RE, Becker S (1982) Seasonal changes in nutritional status and the prevalence of malnutrition in a longitudinal study of young children in rural Bangladesh. Am J Clin Nutr 36:303-313

Carlquist A, Erling V, Ashraf R, Frisén M, Hanson LÅ, Jalil F, Zaman S (1999) The impact of season and climate on growth during early childhood in different socio-economic groups in Lahore, Pakistan. Department of Statistics, Göteborg University, Göteborg

Chotard S, Mason JB, Oliphant NP, Mebrahtu S, Hailey P (2010) Fluctuations in wasting in vulnerable child populations in the Greater Horn of Africa. Food Nutr Bull 31:S219-S233

Costello AM (1989) Growth velocity and stunting in rural Nepal. Arch Dis Child 64:1478-1482

de Onis M, Siyam A, Borghi E, Onyango AW, Piwoz E, Garza C (2011) Comparison of the World Health Organization growth velocity standards with existing US reference data. Pediatrics 128:e18-e26

De Sherbinin A (2011) The biophysical and geographical correlates of child malnutrition in Africa. Popul Space Place 17:27-46

Ferro-Luzzi A, Morris SS, Taffesse S, Demissie T, D'Amato M (2001) Seasonal undernutrition in rural Ethiopia- magnitude, correlates, and functional significance. International Food Policy Research Institute, Washington DC

Fishman SM, Caulfield LE, de Onis M, Blössner M, Hyder AA, Mullany L, Black RE (2004) Childhood and maternal underweight. In: Ezzati M, Lopez AD, Rodgers A, Murray CJL (eds) Comparative quantification of health risks- global and regional burden of disease attributable to selected major risk factors, vol 1. World Health Organization, Geneva, pp 39-161

Franquin P, Diziain R, Cointepas JP, Boulevert Y (1988) Agroclimatologie du Centrafrique. ORSTOM, Paris

Garenne M, Willie D, Maire B, Fontaine O, Eeckels R, Briend A, Van den Broeck J (2009) Incidence and duration of severe wasting in two African populations. Public Health Nutr 12:1974-1982

Gill GJ (1991) Seasonality and agriculture in the developing world : a problem of the poor and powerless. Cambridge University Press, Cambridge

Guo SM, Roche AF, Fomon SJ, Nelson SE, Chumlea WC, Rogers RR, Baumgartner RN, Ziegler EE, Siervogel RM (1991) Reference data on gains in weight and length during the first two years of life. J Pediatr 119:355-362

Hauspie RC, Pagezy H (1989) Longitudinal study of growth of African babies: an analysis of seasonal variations in the average growth rate and the effects of infectious diseases on individual and average growth patterns. Acta Paediat Scand Suppl 350:37-43

Hawkins E, Sutton R (2012) Time of emergence of climate signals. Geophys Res Lett 39, L01702

Hillbruner C, Egan R (2008) Seasonality, household food security, and nutritional status in Dinajpur, Bangladesh. Food Nutr Bull 29:221-231

IPCC (2014) Climate Change 2014: Impacts, Adaptation, and Vulnerability. In: Barros VR, Field CB, Dokken DJ, Mastrandrea MD, Mach KJ, Bilir TE, Chatterjee M, Ebi KL, Estrada YO, Genova RC, Girma B, Kissel ES, Levy AN, MacCracken S, Mastrandrea PR, White LL (eds) Part B: Regional Aspects. Contribution of Working Group II to the Fifth Assessment Report of the Intergovernmental Panel on Climate Change. Cambridge University Press, Cambridge, United Kingdom and New York, NY, USA, pp 688

Jalil F, Karlberg J, Hanson LA, Lindblad BS (1989) Growth disturbance in an urban area of Lahore, Pakistan related to feeding patterns, infections and age, sex, socio-economic factors and seasons. Acta Paediatr Scand Suppl 350:44-54

Kandala NB, Madungu TP, Emina JB, Nzita KP, Cappuccio FP (2011) Malnutrition among children under the age of five in the Democratic Republic of Congo (DRC): does geographic location matter? BMC Public Health 11:261

Karlberg J, Ashraf RN, Saleemi M, Yaqoob M, Jalil F (1993) Early child health in Lahore, Pakistan: XI. Growth. Acta Paediatr Suppl 82 Suppl 390:119-149 
Kigutha HN, van Staveren WA, Veerman W, Hautvast JG (1995) Child malnutrition in poor smallholder households in rural Kenya: an in-depth situation analysis. Eur J Clin Nutr 49:691-702

Kismul H, Schwinger C, Chhagan M, Mapatano M, Van den Broeck J (2014) Incidence and course of child malnutrition according to clinical or anthropometrical assessment: a longitudinal study from rural DR Congo. BMC Pediatr 14:22

Lindtjorn B, Alemu T, Bjorvatn B (1993) Dietary pattern and state of nutrition among children in drought-prone areas of southern Ethiopia. Ann Trop Paediatr 13:21-32

Loutan L, Lamotte JM (1984) Seasonal variations in nutrition among a group of nomadic pastoralists in Niger. Lancet 1:945-947

Mahlstein I, Knutti R, Solomon S, Portmann RW (2011) Early onset of significant local warming in low latitude countries. Environ Res Lett 6:034009

Maleta K, Virtanen SM, Espo M, Kulmala T, Ashorn P (2003) Seasonality of growth and the relationship between weight and height gain in children under three years of age in rural Malawi. Acta Paediatr 92:491-497

Marin CM, Segura JL, Bern C, Freedman DS, Guillermo Lescano A, Benavente LE, Cordero LG, Clavijo L, Gilman JB (1996) Seasonal change in nutritional status among young children in an urban shanty town in Peru. Trans R Soc Trop Med Hyg 90:442-445

McGregor IA, Rahman AK, Thompson B, Billewicz WZ, Thomson AM (1968) The growth of young children in a Gambian village. Trans R Soc Trop Med Hyg 62:341-352

Miller J, Ritchie B, Tran C, Beggs S, Lada CO, Whetter K, Cobiac L (2013) Seasonal variation in the nutritional status of children aged 6 to 60 months in a resettlement village in West Timor. Asia Pac J Clin Nutr 22:449-456

Ministère du Plan et Macro International (2008) Enquête Démographique et de Sante, République Démocratique du Congo 2007. Ministère du Plan et Macro International, Calverton, Maryland, USA

Morton JF (2007) The impact of climate change on smallholder and subsistence agriculture. Proc Natl Acad Sci U S A 104:19680-19685

Nikoi E, Anthamatten P (2013) An examination of environmental correlates with childhood height-for-age in Ghana. Public Health Nutr 16:46-53

O'Neill SM, Fitzgerald A, Briend A, Van den Broeck J (2012) Child mortality as predicted by nutritional status and recent weight velocity in children under two in rural Africa. J Nutr 142:520-525

Olusanya BO, Renner JK (2011) Predictors of growth velocity in early infancy in a resource-poor setting. Early Hum Dev 87:647-652

Panter-Brick C (1997) Seasonal growth patterns in rural Nepali children. Ann Hum Biol 24:1-18

Pinstrup-Andersen P (2009) Food security: definition and measurement. Food Security 1:5-7

Prentice AM, Cole TJ (1994) Seasonal changes in growth and energy status in the Third World. Proc Nutr Soc 53:509-519

Rosetta L (1988) Seasonal changes and the physical development of young Serere children in Senegal. Ann Hum Biol 15:179-189

Schaible UE, Kaufmann SH (2007) Malnutrition and infection: complex mechanisms and global impacts. PLoS Med 4:e115

Tomkins AM, Dunn DT, Hayes RJ, Bradley AK (1986) Seasonal variations in the nutritional status of urban Gambian children. Br J Nutr 56:533-543

UNEP (2011) The Democratic Republic of the Congo. Post-conflict environmental assessment- synthesis for policy makers. United Nations Environment Programme, Nairobi

UNICEF (1998) The state of the world's children. UNICEF, New York

Vaitla B, Devereux S, Swan SH (2009) Seasonal hunger: a neglected problem with proven solutions. PLoS Med 6:e1000101

Van den Broeck J (1994) Assessment of child health and nutritional status in a rural tropical area. Doctoral thesis. University of Leuven, Department of Pediatrics

Van den Broeck J, Eeckels R, Massa G (1996) Maternal determinants of child survival in a rural African community. Int J Epidemiol 25:998-1004

van't Hof MA, Haschke F, Darvay S (2000) Euro-Growth references on increments in length, weight, and head and arm circumferences during the first 3 years of life. Euro-Growth study group. J Pediatr Gastroenterol Nutr 31 Suppl 1:S39-S47

Victora CG, de Onis M, Hallal PC, Blossner M, Shrimpton R (2010) Worldwide timing of growth faltering: revisiting implications for interventions. Pediatrics 125:e473-e480

Walker SP, Golden MH (1988) Growth in length of children recovering from severe malnutrition. Eur J Clin Nutr 42:395-404
Wand H, Lote N, Semos I, Siba P (2012) Investigating the spatial variations of high prevalences of severe malnutrition among children in Papua New Guinea: results from geoadditive models. BMC Res Notes 5:288

WHO (2006) WHO child growth standards: methods and development: length/ height-for-age, weight-for-age, weight-for-length, weight-for-height and body mass index-for-age. World Health Organization Multicentre Growth Reference Study, Geneva

WHO (2007) WHO child growth standards: head circumference-for-age, arm circumference-for-age, triceps skinfold-for-age and subscapular skinfold-forage: methods and development. World Health Organization, Geneva

WHO (2009) WHO child growth standards- growth velocity based on weight, length and head circumference: methods and development. World Health Organization, Geneva

WHO, WMO (2012) Atlas of health and climate. World Health Organization, Geneva

Wright J, Vaze P, Russell G, Gundry SW, Ferro-Luzzi A, Mucavele P, Nyatsanza J (2001) Seasonal aspects of weight-for-age in young children in Zimbabwe. Public Health Nutr 4:757-764

Xu X, Wang WP, Guo ZP, Cheung YB, Karlberg J (2001) Seasonality of growth in Shanghai infants $(n=4128)$ born in 11 consecutive years. Eur J Clin Nutr $55: 714-725$

\section{doi:10.1186/s40322-014-0026-8}

Cite this article as: Schwinger et al:: Seasonal and spatial factors related to longitudinal patterns of child growth in Bwamanda, DR Congo. Earth Perspectives 2014 1:26.

\section{Submit your manuscript to a SpringerOpen ${ }^{\odot}$ journal and benefit from:}

- Convenient online submission

- Rigorous peer review

- Immediate publication on acceptance

- Open access: articles freely available online

- High visibility within the field

- Retaining the copyright to your article

Submit your next manuscript at $>$ springeropen.com 